\title{
The Recognition of Nature in International Relations
}

\author{
Emilian Kavalski and Magdalena Zolkos
}

We are caught in an inescapable network of mutuality, tied in a single garment of destiny. Whatever affects one directly, affects all indirectly.

Martin Luther King, Jr. (16 April 1963)

\section{Introduction}

The prevailing notion of recognition in International Relations (IR) refers to the collective endowment of states with a legal status as legitimate international actors (Griffiths 2013: 716-17; Onuf 2013). Within the Westphalian framework of the discipline, the mutual recognition of and by states has thus been the mechanism through which one's participation in the international society of states is simultaneously validated and formally guaranteed in international law. More recently, however, there have been attempts at conceptualizing a less state-centric notion of recognition. This includes arguments that recognition constitutes a pivotal normative-institutional framework in post-conflict transformation (Lindemann and Ringmar 2011; O'Neill 2012); that it is one of the operative principles of the international human rights regime (Hayden 2012); and that it illuminates the dynamics of normative power in non-Western contexts (Kavalski 2013, 2014). Others have utilized the critical theory of recognition - as developed primarily, though not exclusively, by Alex Honneth - to illuminate how the 'institutionalized recognition order[s]' of immigration policies or of the sociopolitical practices of citizenship are challenged by emancipatory struggles for recognition (Cox 2012; Heins 2012b). 
However, there have been few attempts at applying the concept of recognition in IR to provide an inclusive account not just of the human, but also of the nonhuman interactions in global life (Cudworth and Hobden 2011). This chapter aims to address the issue of recognizing nature as an actor ${ }^{1}$ in international life - by which we mean the ontological and political reorientation of IR to make itself open and responsive to non-human agency (cf. Hobden 2015). We use the concept of 'nature' not in an essentialized sense, but as a framework providing 'an independent domain that both enables and constrains human activities, and [that] will not prove endlessly adaptable to the demands made on it by human beings' (Soper 2010: 223). Nature, therefore, acts as 'the inherent force which directs either the world or humans or both' (Williams 1983: 16-17). Consequently, humans and their activities are not removed from nature, but rather coincide on a 'site, habitat, or medium of ecological interaction and encounter' (Hayden 1998: 115).

Such an engagement with nature should not be new to IR - in fact, it is IR scholarship that has raised awareness of nature's place as 'the primary agent of Western politics' (Rowe 2003: 644). While the location of nature in IR discourses will shortly be addressed at length, it is worthwhile pointing out here that already in the 1950s Harlan and Margaret Sprout were outlining their 'ecological viewpoints, concepts, and theories in connection with politics in general and international politics in particular. The Sprouts defined world politics as a turbulent set of 'man-milieu relationships', which includes 'both tangible objects, non-human and human, at rest and in motion, and the whole complex of social patterns, some embodied in formal enactments, others manifest in more or less stereotyped expectations regarding the behaviour of human beings and the movements and mutations of non-human phenomena' (Sprout and Sprout 1956).

Some recent instances of nature recognition in international life include the incorporation of climate protection into the constitutional arrangements of the Dominican Republic, Ecuador and Tunisia. These instances exceed an earlier trend to constitutionalize 'the right to live in a healthy environment', which reduces the environment to a human right and does not recognize its agential qualities (Aulakh 2014). Instead, recent constitutionalizations of climate protection reflect the emergence of nascent international environmental legislation, including the use of the International Court of Justice for complaints regarding other states' emissions levels, as well as create the possibility for granting refugee status on the grounds of climate change. In the case of emerging 'Earth jurisprudence' (cf. Berry 2002; Litfin 1997; Stutzin 2002), the term 'recognition' signifies more than simply awareness or acknowledgement of nature as a factor in international life. 
Rather, at stake is a declaratory and constitutive act that launches a new state of affairs (cf. Onuf 2013: 126).

The wider intellectual and political context of this investigation is the interdisciplinary debate about the Anthropocene. Anthropocene is an informal descriptor of the current geological era, which draws attention to the unprecedented impact - from the point of view of Earth's history - of human species and their activities on the planet's climate, biodiversity and environment. In short, the label of the Anthropocene suggests that the human species has become a geological force in terms of its capacity for affecting Earth's processes (Chakrabarty 2009; Crutzen and Stoermer 2000). At the same time, it is often overlooked that the Anthropocene functions as shorthand for a new system of planetary inequality, whose 'terraformative power' according to Timothy Luke (2003) enforces 'asymmetries between different populations of humanity and aggregations of nonhumanity'. In particular, current global patterns of commodity production and consumption are:

subjecting objects and subjects to exchange and forcing everyone and everything to perform within the ways of the market. Whether it is bioengineering new life forms, remixing the composition of the planet's atmosphere, or crowding out most other organisms within Earth's carrying capacity, human economic exchanges are now a key environizing power that encircles, contains, and envelops living and nonliving things in the human nations and environmental niches that now constitute the world's ecosystem. (Luke 2003: 393-5)

The reference to the Anthropocene should not be misunderstood, however, as an insistence on the similarity of human and non-human systems. On the contrary, the notion of the Anthropocene does not deny the qualitative distinctions between these two systems. Instead, it underscores that they are mutually implicated and interdependent. This study intends to remind the IR mainstream that human vulnerabilities in the face of climate change are intimately and intricately entwined with those of other beings, rather than separate from them (Mitchell 2014: 13). Furthermore, the attention to shared suffering also helps to bring realization of what James Rowe (2003) has aptly called 'the mutual paradox [of] how the nonhumanities of human design are unevenly transforming both human and natural worlds into new interenvironments'. The interenvironments of planetary inequality that define the Anthropocene help reveal that 'nature is now a near perfect register for continued colonizations that simultaneously serve as portals into the location and scale of ecological destruction' (Rowe 2003: 642-3). 
This investigation takes its starting point in Onuf's redefinition of recognition beyond the state-centric position as a 'way of talking about a constitutive event [in IR] of a transformative potential' (2013). The suggestion is that the terms 'constitutive event' and 'transformative potential' can be contested as not necessarily human-centric, but, potentially, ecocentric and/or biocentric. ${ }^{2}$ More broadly, this interpretative move follows an approach outlined by Kompridis (2007), for whom the key question in recognition debates is not, as has been traditionally assumed, whether or not recognition is oppositional to redistribution, but rather, how the normative sociopolitical principle of recognition is construed and becomes operative. In this way, the chapter explores the construction and operation of the concept of recognition when applied to the agency of nature in international life. At the same time, this study also contests the anthropocentric assumptions of IR by challenging it to both recollect and reengage with its non-anthropocentric ontology and origins.

The attempt to inscribe recognition within the post-human discourse is related, at least partly, to the critique of (what Nancy Fraser calls) 'the KeynsianWestphalian frame [of justice]', which has been solely concerned with 'relations among fellow citizens [and] internal status hierarchies' (2008b: 13). According to Fraser, insofar as globalization has been transforming the contemporary political imagination of what justice is, one needs to consider not only the firstorder questions of the object and subject of recognition, but also the meta-issue of how recognition is 'framed' (2008b: 15). As Fraser elaborates elsewhere admittedly making no reference to other-than-human agency - at stake is the construction of a 'new grammar of political claims-making', where the question of the frame means addressing misrecognition as not simply exclusionary social practice (of, for instance, the agency of nature in IR), but also as monopolization of the symbolic-political production of externality (cf. Fraser in Nash and Bell 2007: 74-7). As instanced by Cudworth and Hobden (2011: 140), the inclusion of environmentalism as an 'issue' of security effectively buttresses the anthropocentric bias of IR either by incorporating nature as a 'support system' for the human world, or by objectifying it as an 'environmental threat' undermining the integrity of the state, as exemplified by the so-called 'resource/climate wars' (see Dyer 2008; Klare 2002; van der Molen and Hildering 2005; Welzer 2012). Instead, what is needed is a posthuman way of thinking about nature recognition (and nature misrecognition) in international life, subject to biocentric and/or ecocentric lines of inquiry and premised on a methodological move away from 'shallow' concerns for environmental issues of inter- and intrastate conflict and cooperation and towards 'deeper' preoccupations with systemic diversity, 
interconnectivity and symbiosis that cut across the traditional positivist thinking about the bifurcation between the human and the non-human. As we indicate, such a project, while demonstrating the limits of anthropocentric thinking about international life, is actually not new to IR - in fact, in its early days, the disciplinary inquiry used to be much more disposed to recognize the agency of nature than it is willing to do today.

\section{Nature in international relations}

The problems associated with the dynamic patterns of climate change and their unintended consequences have challenged conventional capacities for comprehension and have demonstrated the fickleness of established models for their management. In fact, the growing impact of environmental contingencies on everyday lives has demanded a reconsideration of the relationship between sociopolitical and biophysical systems. This pattern seems to confirm Ernst Haas' hunch that 'ethical choices have evolutionary consequences' (Haas 1975: 843). Yet, while 'the state of nature' is no longer just a fictional narrative but 'the most pressing of practical issues' (Booth 2007: 327), the IR mainstream appears to offer little, if any, attention to the agency of nature in international life (Hobden 2015; Hovden 1999; Kavalski 2011).

The claim here is that this has not always been the case. Thus, while a pressing contemporary concern, the environment is actually not a new preoccupation for IR. In fact, it used to have an important place in the study and practice of international affairs. For instance, already in the 1920s, the discipline felt comfortable acknowledging that the natural environment is one of the key actors on the international stage. As Raymond Garfield Gettell insisted, despite 'man's best efforts to bring the world in which he lives under his control, the influence of the natural environment upon political evolution has been throughout all human history an important and, in many instances a decisive, factor... Battles, upon whose outcome the fate of nations has depended, have been decided by natural phenomena such as wind, rain, fog or snow, beyond human control' (Gettell 1922: 322).

In this sense, already from its outset, IR demonstrates no squeamishness about acknowledging that nature's agency - even if unintentional - plays an important role in the unfolding of world affairs (and should therefore not be discarded). For instance, it is often overlooked that with his emphasis on the geographic causation [behind] the competing forces in current international 
politics', Halford Mackinder, the so-called father of geopolitics, intended not only to draw attention to the crucial role played by geography, but rather 'to exhibit human history as part of the life of the world organism. He therefore went on to suggest that the conduct of world affairs reveals that 'man and not nature initiates, but nature in large measure controls [the outcomes]' (Mackinder 1904: 422). Thus, the actorness of nature in the study and practice of IR has urged Ernst Haas to proclaim that international politics... is becoming synonymous with man's efforts to carve out a pattern of coexistence with his biological and physical environment. International politics becomes ecopolitics' (Haas 1975: 853; emphasis added). Likewise, and at about the same time (although in a much more normative vein), Sprout and Sprout (1971) insisted that the IR conversation should be moving 'toward a politics of the planet Earth'.

These statements offer a surprisingly contemporary description of global affairs at the start of the twenty-first century. The rearticulation of international politics as ecopolitics questions the ontological underpinnings of IR. In fact, it calls for

a major revision of our understanding of international relations: Politics among and above nations is recognised as a part of a vast natural system, a biosystem. Therefore, all past units we [have] become accustomed to - territorial units and functional relationships - are subsumed under the biosystemic perspective. All units and all relationships become relevant. (Haas 1975: 842)

This perspective seems to fly in the face of all that IR has grown accustomed to since the end of the Second World War. Premised on the belief in human rationality and a fundamentally physical order, the disciplinary mainstream has uncritically subscribed to an Enlightenment 'faith in a "makeable world" that is, the conviction that it is not only possible, but in fact mandatory to construct a secure, stable and predictable environment for human activity (Kavalski 2009, 536). Thus, the mainstream ontological purview of IR has been underpinned by the perception that human/sociopolitical systems (such as civil society, states, international organizations, etc.) are simultaneously detached from (not only conceptually, but in practice) and in control of the 'nonhuman' natural/biophysical systems within which they are embedded. In this respect the mainstream disciplinary conversation has been concerned only with 'the human subject' (and especially, with willed - that is, intentional - human/ sociopolitical phenomena) and its anthropomorphized effects (such as states and their alliances).

Thus, despite the intellectual challenges posed by the growing interdependence and connectedness between human and non-human systems 
in the Anthropocene, the mainstream of IR research has been, on the one hand, dominated by the deterministic and parsimonious tools of the traditional reductionist mode of investigation and, on the other hand, underpinned by an inherent anti-biologism (if not biophobia). In this setting, the recognition of nature gains its significance to the theory and practice of IR, because it is only when 'environmental factors [are] being perceived and taken into account in the policy-forming process' (Sprout and Sprout 1965) that there can be hope for ethical adaptation to the challenges of the Anthropocene. It has to be acknowledged, however, that Haas was not quite sanguine about IR's capacity to tackle the challenges underpinning the need for an ecopolitical transformation of the discipline. As he put it, this requirement 'is not matched with a political recognition of the problem. The knowledge to bring about recognition exists. But the political institutions for acting on the knowledge do not. Hence, we are headed toward ecological catastrophe' (Haas 1975: 853).

\section{Recognition of nature in international life}

What does it mean, then, to grant nature a recognizable status as an agent in international life? In general terms, as Bennett suggests (2003), at stake in such an inquiry is a 'recognition of the agential powers of natural and artifactual thinking, the greater web of their connections with each other and with human bodies, and... a more cautious, intelligent approach to our interventions in that ecology'. In the following, we elaborate on three distinct, yet mutually constitutive, conceptualizations of nature recognition in the theory and practice of IR. These are, respectively, (a) recognition of vulnerability and resilience of human and non-human systems and life forms; (b) recognition as respect; and (c) mutuality in the recognition-relation.

\section{Vulnerability/resilience/loss}

W. Neil Adger et al. (2011) propose a conception of nature recognition that goes beyond the conventional acknowledgement of the material and economically quantifiable aspects of climate change and, instead, insist on cognizance of the incalculable, symbolic and non-material cultural and ecological loss of plurality of life modes, their interconnectivity, co-relationality and symbiosis. This loss confirms the shared individual and collective precarity of human life and nature in the Anthropocene. The attractiveness of recognition theory for the 
conceptualization of nature in IR lies precisely in its challenge to think of both human and non-human life in terms of their cross-sectionality, interdependence and mutual vulnerability.

At the affective level, the acknowledgement of loss is thus expressed as mourning and grief for the irretrievable demise of non-human entities (Cunsolo Willox 2012; Roelvink and Zolkos forthcoming). The recognition of nature understood in terms of this affective response to the human-induced environmental and climatic change is significant insofar as it entails an act of validation of nature as a subject of mourning. The demise of non-human life forms is declared 'grievable' (see Butler 2004) in the sense of being 'capable of degradation, destruction and suffering' (Cunsolo Willox 2012: 147). Drawing from the Freudian idea of the 'work of mourning', Cunsolo Willox (2012: 145) reframes mourning as the lived experience of climate change to suggest that in mourning 'we not only lose something that was loved, but we lose our former selves, the way we used to be before the loss... Through this mourning we are open to others - human, animal, vegetal, and mineral - and continually exposed and vulnerable to these bodies'. As a consequence, '[p]olitically, the work of mourning builds on [the] visceral and phenomenological experience of mourning, and challenges us to extend our limits of recognition of "mournable bodies" or "mournable entities" - thus revealing its transformative potential by exposing 'the inherent injustice in silenced deaths' and counteracting the 'derealisation of non-human [destruction]' (Cunsolo Willox 2012: 150).

Within the traditional (anthropocentric) IR framework, the importance of mournful affects and their mobilization of, and impact on, political processes, has long been recognized. For example, the mourning of lives lost in the Holocaust has led to the establishment of international anti-genocide legislation, which not only aimed to prevent the recurrence of similar acts, but also made possible the placing of limitations on the principle of state sovereignty by sanctioning different forms of external interference, including humanitarian intervention, to protect the citizens of states from the deeds of their governments. The project of nature recognition in IR means that not only human, but also non-human life is considered to be a potential subject of grief and, as such, generative of the politics of mourning - and, hence, international action.

One of the 'places at risk' owing to climate change are the Pacific Atolls, where the radical transformations of climate patterns have threatened the islands' 'unique biophysical systems and species;... unique material cultures, social orders, diets, stories, languages, habits, and skills', causing migrations for the islanders, the loss of home, habitat and identity insofar as it is place-based 
(Adger et al. 2011: 6; see also Barnett and Chamberlain 2010; Vidal 2013). ${ }^{3}$ Here the point is that within the current parameters of climate change, recognition of nature inevitably entails recognition of a certain loss of nature. This in turn indicates the need to rethink the 'meaning and practice of [international] justice' beyond considerations of state-centred approach to climate change 'solution', and beyond the human rights approach (Adger et al. 2011: 18). The grievable affects animated by the lived experience of loss of the Pacific Islanders have surfaced at international fora; for example during the 2009 climate change negotiations in Copenhagen when Ian Fry, one of the representatives of the Tuvalu delegation, wept during his speech. Notably, the 'emotional outpouring of grief in a largely scientific and political setting served to disrupt the conversations momentarily, and to cause discomfort' (Cunsolo Willox 2012: 152). Equally importantly, it served as a powerful indication of the discursive absence in IR of emotive and affective expressions of environmental loss, which can potentially contribute to the recognition of the mutual vulnerability of human and non-human lives (see Farbotko and McGregor 2010).

While one pole of nature recognition is mutual vulnerability, the other one is resilience and adaptation to change of human and other-than-human systems. More specifically, for Adger et al. (2011: 5) nature recognition means not only acknowledgement of shared precarity, but also consideration of 'traditional ecological knowledge', that is 'systems of practice and belief of how the natural world works', for increasing resilience and for the implementation of change, adaptation and learning. In the example of the Pacific Atolls, the adaptive strategies, while limited, include (a) 'relatively high degree of reciprocity among people, communities, and neighbouring islands [which] facilitates the kinds of exchanges of materials and information that assists in coping with surprises'; (b) 'a long history of exposure to short-term environmental perturbations, [which has produced] various strategies that enable learning and adjustment'; and (c) 'a high degree of traditional ecological knowledge, and...opportunities for building on traditional resource management institutions' (Adger et al. 2011: 7). The islands have made transition to renewable energy sources, including the locally produced coconut-derived biodiesel and are undergoing infrastructural conversion to solar energy (Vidal 2013).

Furthermore, these two elements of nature recognition - the shared biospherical vulnerability and the cross-species resilience and adaptability focus attention on the prospects and possibilities for generating ecocentric (rather than anthropocentric) solidarity in international life. The recognition of human and non-human interdependence and mutual vulnerability underscores shared 
interests and articulates a vision of biotic togetherness, or an international posthuman community. To imagine community in ecological terms means thus that human systems are understood in composition with nonhumanity, never outside of a sticky web of connections' (Bennett 2003: 365). The idea of nature recognition as a base for an international posthuman community formation is premised on the post-Cartesian dislodging of humanity from its separate and hierarchical location. ${ }^{5}$ Cunsolo Willox (2012: 157) calls such community the 'ecological democracy-to-come', which 'both includes and recognizes animal, vegetal, and mineral bodies and ecosystems' and has 'a potential to create a more fully inclusive political order'.

\section{Recognition as respect}

Contributing to the debates in environmental justice, David Schlosberg (2004, 2007) turns to critical recognition theory in order to spell out a vision of international life where the diversity of agency not only goes beyond the statecentric domain, but also combines systemic elements of human and nonhuman interactions. This take on the project of nature recognition pivots on the notion and practices of respect. Within recognition theory, respect has been articulated in the context of democratic accommodation of difference (cf. Taylor 1994). On the one hand, respect functions as a way of trumping the pressures of cultural assimilation and/or stigmatization of peripheral identities. On the other hand, it assists with avoiding the perils of isolationism. Thus, in line with the Hegelian tradition of recognition, the respect for cultural difference can be extended to include respect for the irreducible uniqueness and specificity of diverse life forms. This assists the positioning of human species as belonging to (but not above) a non-human community of global life in which 'each individual living thing [is] a teleological centre of life, [as] "striving for life"' (Taylor 1986).

It is necessary to qualify here that recognition as respect is often (and erroneously) treated as synonymous with recognition as similarity. As Emmanuel Levinas (1969) suggests, the latter approach treats recognition as the elimination of the radical difference of the other by reducing it to 'sameness'. It is for this reason that Levinas perceives recognition as a form of violence against the other (McQueen 2011). In the context of international politics, the 'similarity approach' implies that the recognition of non-human actors can occur only to the extent that there is some resemblance between them and human actors. The issue here usually is sentience - in particular, that it is not an exclusively human quality; hence, non-human actors who possess it should be treated similarly to 
us (Schlosberg 2007: 133-6). An example of recognition as similarity is the 2010 Declaration of Rights for Cetaceans drafted in Helsinki, which affirms whales and dolphins as 'persons [who] have the right to life, liberty and well-being' The declaration has garnered not only activist and scientific support, but has also been adopted in government initiatives such as the 2013 recognition of dolphins as 'non-human persons' by India (Coelho 2013). On similar grounds, in 2008, the Spanish Parliament acknowledged the 'non-human rights' of apes (Glendinning 2008), while at the end of 2014 an orangutan in Argentina has been granted the basic rights of a 'non-human person', including the right to be freed from its captivity at the Buenos Aires zoo (BBC 2014). In this setting, while commendable, premising the recognition of nature's actorness on its resemblance to the human subject is problematic, because it indirectly affirms the superiority of the human as the norm (cf. Weitzenfeld and Joy 2014: 10).

In contrast, recognition as respect defies the assimilative logic of the similarity approach by virtue of its insistence on the necessity of difference between the other and the self for the 'mediated self-affirmation to be successful' (Yar 2002: 69). In this interpretation recognition can only take place between two subjects. Borrowing from Henry Thoreau's concept of 'the Wild', Bennett (2003:348; Bennett 1994) suggests that 'there is an existence peculiar to a thing that is irreducible to the thing's imbrication with human subjectivity'. In the act of nature recognition the self encounters her/his other - or 'the Wild' - which in turn connotes the 'startling element of foreignness in every object of experience, however familiar' (Bennett 1994). Consequently, the emphasis on respect suggests that the key component of recognition is structural, and not psychological: recognition aims at overcoming institutionalized subordination and exclusion, rather than at preventing or undoing some 'oppressive psychological harm' (Schlosberg 2004: 537). At the same time, the politics of respect forges opportunities for overcoming the 'insidious silencing' of the non-human through the 'recognition of agency in nature' (Dryzek 2000: 149; Friskics 2001).

In this context, nature recognition entails respect for the other-than-human life (in reference to individual living beings, as well as ecological systems), with the goal of 'extending the community of [international] justice, and moving beyond the focus on the human use of nonhuman nature' (Schlosberg 2007: 133). ${ }^{6}$ In turn, this calls for examination of the 'underlying social, cultural, and political issues around ... the recognition of nature' (Schlosberg 2007: 132). Such a take reveals the inherent emancipatory potential of the project of recognition. It is with this in mind that the following section draws attention to the issue of mutuality. 


\section{Recognition and mutuality}

As already indicated, the development of a more nuanced articulation of recognition in the IR literature has drawn from the critical theories of recognition (such as Taylor, Honneth and Fraser), which have their origins in the Hegelian concept of selfhood. At the heart of the Hegelian tradition is the suggestion that human beings acquire social existence intersubjectively and dialogically (Fraser and Honneth 2003; McQueen 2011). As Hegel himself famously declared in The Phenomenology of Spirit (1977), recognition entails the achievement of self-consciousness and affirmation of one's autonomy and freedom in relation to others - that is, the emergence of a subject 'with particular characteristics, traits, qualities and features, in short the establishment of one's self-understanding... is inextricably dependent on recognition or affirmation on the part of others' (Yar 2002: 59). In the Philosophy of Right, Hegel (1967) positions recognition at the centre of ethical life: 'ethical subjects are constituted through the process of recognition...the mechanisms of ethical constitution are relational in nature, not simply originating in subjective rationality' (Barkdull and Harris 1998; Thompson 2013: 320).

While the Hegelian imaginary of the subject of recognition is explicitly human-centric (insofar as its agent is defined by features such as autonomy, intentionality and freedom, which have traditionally served the humanist ontology to mark the human distinction from nature; see e.g. Benjamin 2011; Oliver 2009; Wolfe 2009), this tradition nevertheless helps to suggest that the recognition of non-human actors in international life requires not simply the need to extend the concept of recognition beyond the agency of the state, but rather the requirement for its radical reframing 'beyond-the-human' into a nonanthropocentric conception of international life. According to Iser (2013), '[m] utuality has always served as the explanatory and normative core of the concept of recognition. This explanatory and normative core of mutuality reveals recognition as a relational process which 'cannot be coerced but [must] be freely given and received, as being at home in the other' (McQueen 2011). In particular, the emphasis on mutuality suggests that the basic ontological condition of all international actors - be they human or otherwise - is relational.

Thus, by recognizing the mutuality between human and non-human systems in IR, it is possible to begin the encounter with global life in the Anthropocene. The contention here is that contemporary world affairs are not merely about who gets what, when and how, but also about the capacity to encounter global life in all its complexity. Such an encounter elicits that all human interactions are located in and made possible by complex global interconnections. In other words, the 
recognition of nature in IR uncovers that the 'world is not divided into territories in which bounded societies of humans live under singular political authority and in the context of discrete natural environments'; instead, global life is 'a complex interweave of numerous systems nested, intersected and embedded in each other, all undergoing processes of co-evolution and linked by innumerable feedback loops' (Cudworth and Hobden 2011: 173, 75).

In this context, the attention to mutuality allows for recognizing the simultaneity, agency and subjectivity of both human and non-human actors on the global stage. The IR inquiry can therefore be reframed as a response 'not only to human actions but also to the actions of plants, animals, stones, rivers, and mountains' (Ruiz 2000: 336). The emphasis on mutuality reveals that the 'international system' is embedded within wider structural conditions and interactions located within the environment surrounding the conventional focus on interstate relations - an environment, which conceptually constitutes as well as causally conditions (although not in a mono-causal and linear fashion) states and other actors (Kurki 2008: 255-61). Human societies and their international interactions are just 'one component in a package of interdependent life forms that continue to adapt to each other' (Clark 2000: 4). The recognition of nature therefore proffers a 'human-in-ecosystem' perspective on the study and practice of IR, which takes as its point of departure 'the mutual influence of ecological and social processes, instead of treating social and ecological systems as linked but separate domains' (Davidson-Hunt and Berkes 2003: 54). Such recognition of the agency of nature in IR also calls for a critical self-review of IR's own investment in anthropocentric ontologies, epistemologies and politics.

\section{Conclusions: The limits of recognition}

In this study we have explored the potential of the concept of recognition to sketch out a useful trajectory for the engagement of non-human agency in international life, as well as, more broadly, for the project of non-anthropocentric IR. This endeavour does not want to brandish the recognition of nature by IR as a panacea for either the crises plaguing the global condition or the flaws of the disciplinary purview; instead, the aim is to indicate that the recognition of nature opens up unique and novel opportunities for a thorough reconsideration of the explanation and understanding of the disciplinary mainstream. At the same time, it also contributes meaningfully to the ethical project of equitable, just, and sustainable living in the era of the Anthropocene. In this context, the 
analysis has drawn attention to the notion of mutuality - the explanatory and normative hallmark of the recognition-relation - as a mode for recognizing the complex interdependence of human and non-human actors. However, the encompassing of nature into the normative framework of recognition needs to consider the anthropocentric roots of the conception of mutuality.

In the Hegelian idea of recognition, from which IR borrows, mutuality is understood primarily as reciprocity (rather than as relational interdependence, as we have proposed) and is used explicitly in reference to human subjects. Such origins suggest some potential limitations of the recognition concept to the nonanthropocentric project of IR.7 According to Hegel (1977: 230) the reciprocal character of recognition asserts mutuality as the double process of both selfconsciousnesses.... Action from one side only would be useless, because what is to happen can only be brought about by means of both. What is being acknowledged in the recognition process is 'another self-consciousness, another human subject' (Thomson 2011: 327). Hence, mutuality implies that recognition is either done or experienced by each party towards the other, and that it is binding or bearing on the parties equally. Nature is, thereby, excluded from the scene of recognition insofar as (drawing on Beauvoir's critique of Hegel's non-inclusion of women in recognition) it is designated as not capable of 'transcendence', and thus of becoming self-conscious in the sense of achieving self-identity as a person (cf. Burke 2005).

More generally, Majid Yar demonstrates that in Kojève's reading of Hegel - one that positions irreducible and radical difference at the heart of the recognition scene - it is precisely the distinction between human and animal that forms the condition of possibility for recognition of the self and other to take place. For Hegel (according to Kojève) it is 'human desire' that brings about recognition; it is "in and by - or better still, as - "his" Desire that man is formed and is revealed - to himself and to others - as an I, as the I that is essentially different from, and radically opposed to, the non-I' (Kojève 1969: 3). What Kojève refers to as the 'anthropogenetic Desire' for the (recognition by) the Other is premised by mutuality not in the sense of 'establishing an identity between myself and other, i.e. in recognizing in her only the very same characteristics I seek to have recognized in myself', but as an affirmation of the Other as a non-assimilative subject. Human desire for recognition means that 'the other has to be deemed capable and worthy of granting recognition... the subject must trust and esteem the other's capacity for judgment, he must value the other's estimations as meaningful, significant and noteworthy' (Yar 2002: 67).

This assertion is based on Kojève's explicit distinction between human desire and animal desire in Hegel, where the latter is a type of object-desire, directed at 
the material conditions that sustain life (food, shelter, etc.). In distinction from human desire, animal desire is directed 'toward a real, "positive", given object', and its primary drive is to internalize, assimilate and possess the object (Kojève 1969: 6). For (Kojève's) Hegel, to base the understanding of mutual recognition on the unnegotiable distinction between human and animal is thus indicative of traditional Western philosophic validation of the other only insofar as otherness and the desire for the other's recognition is taken to be a 'uniquely human concern' (Benjamin 2011: 96). In the Western philosophic tradition the animal (and, more broadly, the natural world) is defined through its inability to grant and receive recognition, just as much as it is unable to respond, or perform acts of meta-communication (cf. Wolfe 2003).

The point here is that just like IR, the theory of recognition is in need of a critical self-review of its own anthropocentric commitments and politics if its transformative potential for the project of nature recognition in IR (and not only) is to be explored. One possible pathway for resolving this quandary is - as we have done in this study - to redefine mutuality as not exclusively tied to the principle of reciprocity, but as an opening to the complex and nuanced ways in which human and non-human environments intersect and affect one another. The resultant ethos of interconnectivity nourishes responsiveness towards other (radically different) kinds of beings (Mitchell 2014: 7-9). ${ }^{8}$

This qualification notwithstanding, the suggestion here is that the recognition of nature in IR offers the potential to disrupt the entrenched human-centred purview of the discipline by urging it to account for the complex interactions between sociopolitical systems and the ecologies that they inhabit. Such an encounter with the embeddedness of international relations within larger systems of global interactions demands 'asking questions about moments of imperial encounter and global governmentality that simultaneously involve multiple cultures and multiple forms of life' (Youatt 2014: 223). Echoing William Connolly's proposition that agency is not the property of individual human beings, but is enabled by a diversity of non-human actors and systems, the normative contention of this study is that the recognition of nature in IR might help us 'find that our attachment to the world also ripens':

We do not seek to belong to an organic world but to heighten our attachment to a world replete with differential degrees of incompleteness and creative possibility. To appreciate our entanglements with a variety of nonhuman forces... may help to ennoble the larger ethos in which we participate. In such a world we are both partial product and constrained participants. (Connolly 2014: 451) 
Such a move would incite IR to abandon its striving for full security, control and predictability, by allowing it to sustain complexity, foster dynamism, encourage the cross-pollination of disparate ideas and engage the plastic and heterogeneous processes that periodically overwhelm, intensify and infect (while all the time animating) the trajectories of human and non-human lives (Anker 2014: 454; Connolly 2014: 447; Kavalski 2015: 5). The recognition of the mutuality between human and non-human systems can thereby assist with lifting the constraints on IR's imagination that currently prevents it from offering original responses to the challenges facing global life in the Anthropocene. The hope is that this study makes a small but meaningful step in this direction. ${ }^{9}$

\section{Notes}

1 Throughout the chapter we use the terminology of 'agent' and 'actor' as stylistic variations. However, we also acknowledge the point made by Bruno Latour (1999) that the terminology of 'actorness' has been traditionally associated with human activity; Latour thus proposes an alternative term of 'actancy' to include both human and other-than-human activity. Following Bennett $(2003: 355,351)$, we seek to reframe the terms of 'actor' or 'agent' in a non-anthropocentric mode as 'that which does something, has sufficient coherence to perform actions, produce effects and alter situations'; and 'the curious ability of inanimate [and animate] things to animate, to act, to produce effects dramatic and subtle'.

2 The difference between the approaches of biocentrism and ecocentrism is not significant for the argument advanced in this study (which is why we use them interchangeably).

3 It is important to acknowledge in this context the literature critiquing the claim that migration patterns in the Pacific can be solely ascribed to climate change. See for example the study by Hau'ofa (1994), which offers a more historically nuanced view on Pacific migrations than we are able to consider in this study. Our thanks to Vicki Flack for bringing this point to our attention.

4 Another example of affective response to climate change, which has recently come to public attention, is the speech by Yeb Sano, the head of the Philippines delegation at the 19th Annual Conference of the Parties (COP) to the UN Framework Convention on Climate Change (UNFCCC) in Warsaw in 2013. In his impassioned appeal to the conference delegates, Sano made a link between the devastating effect of the typhoon Haiyan and climate change, arguing that ' $[w]$ hat my country is going through as a result of this extreme climate event is madness, the climate crisis is madness. We can stop this madness right here in Warsaw' (quoted in McGrath 2013). 
5 This is not to argue for an indistinction between human and non-human international systems. We endorse here the position of Cudworth and Hobden (2011) that posthuman (non-anthropocentric) international relations does not mean that one posits human and nonhuman systems as indistinct and reducible to one another. Rather, and taking inspiration from John Frow (quoted in Bennett 2003: 355), we suggest that the shift is from 'vertical' (and hence hierarchical) structuring of the human and nonhuman systems to the 'horizontal' structuring that presumes juxtaposition and continuum of agencies: the need is to be flattened, read horizontally as a juxtaposition rather than vertically as a hierarchy of being. It's a feature of our world that we can and do distinguish... things from persons [nonhuman and human systems]. But the sort of world we live in makes it constantly possible for these two sets of kinds to exchange properties'.

6 A strand of this understanding of recognition addresses the issue of various forms of non-human sovereignty (Donaldson and Kymlicka 2011; Goodin et al. 1997; Stone 1974). However, such discussions tend to reify rather than break the divisions between human and non-human systems, thereby perpetuating the central features of anthropocentrism.

7 On the limits of the project of recognition in regard to human-animal relations, see Kompridis (2013).

8 Another potentially productive way for decentring the anthropocentric underpinnings of the notion of recognition might be to engage the philosophical debates on 'nonreciprocal recognition' (cf. Burke 2005).

9 The authors would like to thank Vicki Flack, Stephen Hobden and Nikolas Kompridis for their engagement with earlier drafts of this chapter. We also want to thank the participants of the workshop 'Recognition and the International' at St Andrews in April 2014 for their rich comments and discussion of the paper from which this chapter grew, and, in particular, the organizers of the event, Patrick Hayden and Kate Schick, for their intellectual generosity and their work on both the workshop and the edited collection. 
Emilian Kavalski and Magdalena Zolkos - 9781526101037 Downloaded from manchesterhive.com at $04 / 26 / 2023$ 10:23:53AM 